\title{
Echocardiographic alterations in a child with cow's milk allergy: a case report
}

\author{
Giuseppe Di Cara ${ }^{1 *}$, Maria Giulia Berioli ${ }^{2}$, Anna Biscarini ${ }^{2}$, Claudia Soldani ${ }^{2}$, Piera Abate ${ }^{1}$, Eleonora Ugolini ${ }^{1}$, \\ Giusiana Allocca ${ }^{1}$ and Maddalena Milioni ${ }^{1}$
}

\begin{abstract}
Introduction: Cow's milk allergy is the most frequent food allergy in Europe and western countries and shows a wide spectrum of clinical features, including atopic dermatitis and gastrointestinal disease. To the best of our knowledge, this report is the first to describe Kawasaki disease-like clinical features and echocardiographic alterations which resolved after a cow's milk-free diet.

Case presentation: We report a case of a 9-month-old Caucasian girl with atopic dermatitis who developed clinical features commonly present in Kawasaki disease (erythematous skin rash, non-exudative conjunctivitis, fissured lips and neck lymph nodes), together with mild echocardiographic alterations (perivascular brightness, pericardial effusion) in the absence of fever. These features resolved within 2 weeks after the beginning of a cow's milk-free diet.

Conclusion: Kawasaki disease has recently been considered a possible risk factor for subsequent allergic disease secondary to immune dysfunction. This case report suggests that the immune-related alterations which are commonly present in allergic patients could be similar to the antigen-related immune response in Kawasaki disease and thus could lead to similar clinical features.
\end{abstract}

Keywords: Cow's milk allergy, Kawasaki disease

\section{Introduction}

Cow's milk allergy (CMA) is an immunologicallymediated adverse reaction to several allergenic proteins present in cow's milk which affects approximately $5 \%$ to $7 \%$ of children in the first years of life and $2 \%$ to $3 \%$ of adults [1]. Immunological mechanisms leading to this food allergy, which is the most frequent food allergy in Europe and western countries, include immunoglobulin E (IgE)-mediated hypersensitivity and cellular immune response. CMA is commonly a disease of early infancy, with children developing symptoms a few weeks after the introduction of cow's milk-based formula into the diet. The most common features of CMA in the first years of life include atopic dermatitis and gastrointestinal diseases such as food protein-induced enterocolitis and allergic eosinophilic gastrointestinal disorders [2]. We report on a patient with atopic dermatitis and

\footnotetext{
* Correspondence: giu.dicara@gmail.com

${ }^{1}$ Servizio di Immuno-Allergologia Pediatrica, University of Perugia, Perugia 06100, Italy

Full list of author information is available at the end of the article
}

previously undiagnosed cow's milk allergy who was admitted to our hospital with clinical, laboratory and echocardiographic findings frequently present in Kawasaki disease (KD). The absence of fever, a leading feature in the diagnosis of $\mathrm{KD}$, excluded such a diagnosis, and the presence of high specific serum IgE towards cow's milk, together with the negativity of other tests for several infectious diseases, suggested the role of cow's milk allergy in the development of these symptoms.

\section{Case presentation}

A 9-month-old Caucasian girl was admitted to our hospital for the presence of a persistent skin rash and redness of the eyes. Her medical history was positive for mild atopic dermatitis present since 6 months of age. In the 3 weeks prior to admission, she did not have fever. Her physical examination showed an erythematous rash involving the trunk and limbs, fissured lips, erythema of oral mucosa, bilateral conjunctival injection without eye discharge and laterocervical lymph nodes. The respiratory and abdominal examinations were normal. The

\section{() Biomed Central}


cardiac evaluation showed tachycardia with normal heart sounds. The laboratory results revealed a white blood cell count of $8500 / \mathrm{mm}^{3}$ (normal range: 3600 to $9600 /$ $\mathrm{mm}^{3}$ ) with normal differential counts, hemoglobin level of $10.7 \mathrm{~g} / \mathrm{dl}$ (normal range: 11.5 to $14.5 \mathrm{~g} / \mathrm{dl}$ ), platelet count of $376,000 / \mathrm{mm}^{3}$ (normal range: 150,000 to $350,000 / \mathrm{mm}^{3}$ ), erythrocyte sedimentation rate of $35 \mathrm{~mm} /$ hour (normal range: 5 to $25 \mathrm{~mm} /$ hour), C-reactive protein level $1.5 \mathrm{mg} / \mathrm{dl}$ (normal range: 0 to $1 \mathrm{mg} / \mathrm{dl}$ ), albumin level $2.8 \mathrm{~g} / \mathrm{dl}$ (normal range: 3.5 to $5.5 \mathrm{~g} / \mathrm{dl}$ ), alanine aminotransferase $24 \mathrm{U} / \mathrm{L}$ (normal range: 15 to $45 \mathrm{U} / \mathrm{L}$ ), aspartate aminotransferase 27U/L (normal range: 20 to $55 \mathrm{U} / \mathrm{L}$ ), $\gamma$-glutamyl transferase $59 \mathrm{U} / \mathrm{L}$ (normal range: 0 to $35 \mathrm{U} / \mathrm{L}$ ), direct bilirubin $0.4 \mathrm{mg} / \mathrm{dl}$ (normal range: 0.3 to $1 \mathrm{mg} / \mathrm{dl}$ ), IgG 589mg/dl (normal range: 380 to $790 \mathrm{mg} / \mathrm{dl}$ ), IgA $34 \mathrm{mg} / \mathrm{dl}$ (normal range: 20 to $120 \mathrm{mg} / \mathrm{dl}$ ). Serumspecific IgE against cow's milk proteins were positive (12.5kU/L; normal values: 0 to $0.35 \mathrm{kU} / \mathrm{L})$.

The blood culture, urine culture and serology for Epstein-Barr virus, cytomegalovirus, measles, rubella, parvovirus and adenovirus were all negative. Antistreptolysin antibodies were negative. Her chest radiogram was normal. Echocardiography performed at admission showed mild pericardial effusion and perivascular brightness of the proximal left descending coronary artery (Figure 1).

Because of the absence of fever before and during the admission, the diagnosis of KD was excluded. A cow's milk-free diet was started 2 days after admission, which led to resolution of the clinical findings and normalization of the laboratory findings after 1 week. A second echocardiography, performed 2 weeks after the beginning of the diet, was normal. During the 2 weeks of the infant's admission, she never presented fever, and no interventions other than the cow's milk-free diet were necessary.

\section{Discussion}

The relationship between KD and atopy has been evaluated in a large cohort study which evidenced a significantly higher incidence of allergic rhinitis and atopic dermatitis in children who have had KD [3]. Matsuoka et al. proposed that the genetic predisposition to atopy could be associated with a higher susceptibility to KD. In addition, patients with KD tend to have a higher risk of developing atopic dermatitis and allergic rhinitis. Recently, a study of 93 sibling pairs supported the hypothesis of an inherited genetic pattern which increases the risk both of KD and atopy, secondary to an immune disequilibrium which leads to an abnormal inflammatory response to different trigger events [4].

Our report of a child who presented several clinical features of $\mathrm{KD}$, together with mild cardiac echocardiographic alterations, both of which resolved after a cow's milk protein-free diet, underlines the relationship between atopy and KD.

Although most of the clinical features we evidenced were non-specific, as can be present in several infectious diseases (although in this child serological tests were negative for all pathogens causing similar findings), the association with echocardiographic alterations has not been reported previously in children with food allergies.

Our data support the hypothesis that the same heritable genetic factors that induce a specific pattern of altered or impaired immune maturation could increase the risk of developing both KD and allergy.

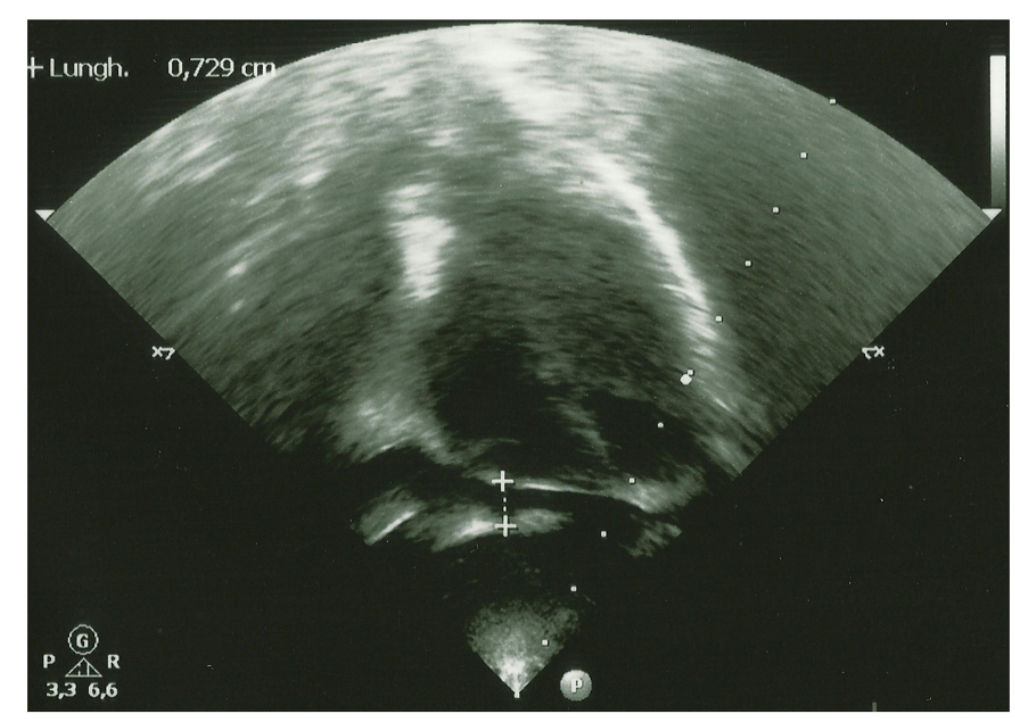

Figure 1 Echocardiographic findings: pericardial effusion and perivascular brightness of the proximal left descending coronary artery. 


\section{Conclusions}

KD has been considered a possible risk factor for subsequent allergic disease secondary to immune dysfunction. We suggest that immune-related alterations which are commonly present in allergic patients such as those with CMA may be similar to the antigen-related immune response in KD and thus could lead to similar clinical features. To the best of our knowledge, this report is the first to describe KD-like clinical features and echocardiographic alterations which resolved after a cow's milk-free diet.

\section{Consent}

Written informed consent was obtained from the patient's parents for publication of this case report. A copy of the written consent is available for review by the Editor-in-Chief of this journal.

\section{Competing interests}

The authors declare that they have no competing interests.

\section{Authors' contributions}

GDC, MGB, AB and CS evaluated the pat+ient during admission and evaluated her during the follow-up period. PA, GA, EU and MM were major contributors to the writing of the manuscript. All authors read and approved the final manuscript.

\section{Author details}

${ }^{1}$ Servizio di Immuno-Allergologia Pediatrica, University of Perugia, Perugia 06100, Italy. ${ }^{2}$ Division of Pediatrics, Azienda Ospedaliera di Perugia, Perugia 06100, Italy.

Received: 23 February 2012 Accepted: 27 July 2012

Published: 13 September 2012

\section{References}

1. Host A: Cow's milk protein allergy and intolerance in infancy. Pediatr Allergy Immunol 1994, 5(Suppl 5):5-36.

2. Host A, Halken S, Jacobsen HP, Christensen AE, Herskind AM, Plesner K: Clinical course of cow's milk protein allergy/intolerance and atopic diseases in childhood. Pediatr Allergy Immunol 2002, 13(Suppl 15):23-28.

3. Matsuoka S, Tatara K, Nakagawa R, Mori K, Kuroda Y: Tendency toward atopy in Kawasaki disease. Eur J Pediatr 1997, 156:30-32.

4. Liew WK, Lim CW, Tan TH, Wong KY, Tai BC, Quek SC, van Bever H: The effect of Kawasaki disease on childhood allergies: a sibling control study. Pediatr Allergy Immunol 2011, 22:488-493.

\section{Submit your next manuscript to BioMed Central and take full advantage of:}

- Convenient online submission

- Thorough peer review

- No space constraints or color figure charges

- Immediate publication on acceptance

- Inclusion in PubMed, CAS, Scopus and Google Scholar

- Research which is freely available for redistribution 